\title{
Supporting Learning Leaders for the Effective Integration of Technology into Schools
}

\author{
Rhonda Christensen \\ University of North Texas, USA \\ Koos Eichhorn \\ Lucas onderwijs, The Netherlands \\ Sarah Prestridge \\ Griffith University, Australia \\ Dominik Petko \\ Pädagogische Hochschule Schwyz, Switzerland \\ Henk Sligte \\ Kohnstamm Institute University of Amsterdam \\ Rowland Baker \\ Santa Cruz County Office of Education, USA \\ Ghaida Alayyar \\ Public Authority of Applied Education and Training, Kuwait \\ Gerald Knezek \\ University of North Texas, USA
}

\begin{abstract}
Learning leaders have important roles in facilitating and supporting the effective and innovative integration of technology in schools. Many leaders who are charged with the task of technology integration have not received professional development to support a leadership role. Many teachers who assume the role of technology leaders develop into this role organically over time based on their recognized performance. School administrators may not have the skills to make decisions for technology integration for learning. Effective ICT learning leaders exhibit the ability to create a shared vision, remain pedagogically focused, and seek and contribute to on-going professional development. Recognizing characteristics of learning leaders who are innovators in technology integration is an important step in the overall improvement of education systems. This paper focuses on the role learning leaders have in the effective use of technology in the learning environment and the types of professional development that best support learning for these leaders. The paper also addresses the important role of
\end{abstract}


assessment, in order to continue the quest to determine what technology-enhanced interventions and innovations work for whom, in what contexts, and under what conditions.

Keywords: learning leaders, technology integration, school leadership, professional development

\section{Introduction}

Technology in education is an integral part of effective teaching and learning. It is crucial to prepare learning leaders who can guide and support innovative and effective technology-enhanced learning in the classroom. To achieve this goal, learning leaders should not focus on adding new technologies to the curriculum, but rather focus on the creation of a culture of change: "It does not mean adopting innovations, one after the other, it does mean producing the capacity to seek, critically assess, and selectively incorporate new ideas and practices - all the time, inside the organization as well as outside it" (Fullan, 2001, p. 44).

Learning technologies should support curricular activities in engaging ways that may not otherwise be possible. Rather than focusing on the technology, learning activities should meet instructional goals and involve technology when the technology enhances learning. Educators may conceptualize integration as technological rather than primarily as curricular (Hutchison \& Reinking, 2011). However, the focus should be on learning and the curriculum, not the technology. 
Researchers investigating factors that impact the effectiveness of technology on learning have found school leadership to be a critical factor (Anderson \& Dexter, 2005). The success or failure of the effective use of technology for learning in schools can be linked to beliefs and ideas of instructional leaders (Chang, 2012; Hughes \& Zachariah, 2001). Leaders need to understand and enact school reform including how to: a) build a shared vision (including elements of ownership, using data, gap analysis, strategies), b) focus on pedagogy appropriate for technology, c) support mentorship/coaches, and d) provide infrastructure (hardware, software, bandwidth, policies).

This paper focuses on the role learning leaders have in the effective use of technology in the learning environment and how to enable and support professional development for these leaders. While acknowledging there are many levels of leadership in a school system (e.g. principals, curriculum specialists, technology coordinators, teacher team leaders etc.), this paper focuses on two groups of leaders who typically have the most direct contact with students - instructional administrators (principals, heads of school, etc.) and teacher leaders. This paper includes the definition, characteristics, roles and preparation of learning leaders who are charged with integrating technology into the learning environment effectively. Innovative practices and models are provided as an example of effective leadership strategies. Finally, assessment for identifying, supporting, and preparing learning leaders as well as implications for practice are included in the final sections of the paper.

\section{Background}


Researchers have called for the need to focus on pedagogical reform for the infusion of technology for the past 20 years (Loveless, 2003; Prestridge, 2007). There is a call for a more unified approach to the development of knowledge, skills and processes which requires that educators are more focused on their pedagogical strategies that enable the how, when and why, of the use of appropriate technologies in ways that enable learning to be active, collaborative, experimental and scaffolded (Harasim, 2012). Technological Pedagogical Content Knowledge (TPACK) has been introduced as a conceptual framework for the knowledge base teachers need to effectively teach with technology (Voogt, Fisser, Tondeur, \& Van Braak, 2012). Consequently, for technology-enhanced learning, learning leaders' pedagogical conceptual frameworks and their styles of guidance in reforming pedagogical practices are at the forefront of their leadership.

More than two decades ago researchers were already investigating the relationship between effective technology use in schools and administrative leaders. Pelgrum (1993) found that principals' attitudes toward technology influenced teachers' perceptions about and integration of technology. Other researchers also found that principals influence teacher classroom technology integration in their schools. Dawson and Rake (2003) found that both the amount and type of principals' technology training had a significant impact on teachers' levels of technology integration. In addition, Stuart, Mills, and Remus (2009) found that school leaders with higher levels of technology knowledge and experience supported technology use and integration in their schools.

Over the past decade nations have come to recognize that the level of technology skills in a nation's workforce is one of the major determinants of a nation's capacity for economic development. A group of world leaders in technology education, working 
through the United Nations Educational, Scientific and Cultural Organization (UNESCO), has produced a framework that allows developing countries to project how much they might need to invest in technology education in order to achieve desired social and economic goals. According to the UNESCO ICT Competency Framework for Teachers (2011, p. 3), modern societies are increasingly based on information and knowledge and therefore need to:

- Build workforces which have ICT skills to handle information and are reflective, creative and adept at problem-solving in order to generate knowledge;

- Enable citizens to be knowledgeable and resourceful so they are able to manage their own lives effectively, and are able to lead full and satisfying lives;

- Encourage all citizens to participate fully in society and influence the decisions which affect their lives; and

- Foster cross-cultural understanding and the peaceful resolution of conflict.

The framework committee pointed out that these social and economic goals are the focus of a country's education system. Learning leaders and those who would cultivate a climate that is nurturing toward these professionals need to be aware of the importance of their core mission, which is fostering the improvement of society as a whole.

Thomas and Knezek (2008) summarized the significance of technology proficiencies for several levels of education system professionals, including learning leaders. The authors emphasized that when technology is integrated across an entire school system, it can serve as a catalyst for transforming education - changing widelyranging areas such as resource strategies, learning tools, communication, planning, operations, management, decision- making, curriculum, and teaching and learning. 
Thomas and Knezek (2008) also pointed out that "school leaders who fail to grasp the magnitude of the professional challenge in ICT leadership for schools may not have a twenty-first century understanding of the implications of technology for teaching and learning, nor technology's role in a successful global economy” (p. 344).

The International Society for Technology in Education released the U.S. National Educational Technology Standards for Administrators (NETS-A) in 2002 with a revision in 2009 (ISTE, 2011); both versions include the need for visionary leadership. In addition, the standards include the need for a digital-age learning culture, excellence in professional practice, systemic improvement, and digital citizenship. Currently a new revision is expected, to be released in 2018 (ISTE, 2018). The ISTE standards have been adopted by many educational leadership programs to guide technology integration models in preparing learning leaders (Richardson, Flora, \& Bathon, 2013).

\section{Innovative Learning Leaders}

Learning leaders may include principals, curriculum specialists, technology coordinators, teacher team leaders, instructional technology specialists, teacher leaders or others charged with enhancing education. As previously described, the focus of this paper is on two leadership roles - school building instructional leaders (principals, heads of school, etc.) and teacher leaders. Leadership positions are often occupied on the basis of prior experiences and activities. In schools, teacher-leaders can be identified in much the same way. No matter who is the designated learning leader in a school, it is important for the learning community to have a shared vision for transforming learning. School culture that emphasizes shared goals and collaboration has been shown to have a positive 
impact on innovative practices and learner-centered pedagogies by teachers

(Jacobson, So, Teo, Lee, Pathak, \& Lossman, 2010). An overall

approach/mindset for learning leaders is to have a curious, creative, and critical

approach to the future of the organization of learning.

\section{Characteristics of Learning Leaders}

Numerous characteristics are required to be a successful leader who supports a creative and critical approach to curriculum leadership underpinned by technology infusion. At the EDUSummIT 2017 - an international collaboration of experts in the field of educational technology - one of the groups whose focus was on learning leaders developed a list of characteristics based on experiences, observations and discussions. While individuals may not be proficient in all of these characteristics, it is beneficial to identify potential leaders who possess many of the following characteristics:

- Learning focused: The improvement of student learning should be the ultimate goal of learning leaders and not the introduction of technology as a means in its own right.

- Practitioner-research / design-based researcher: The leader should be able to engage in a systematic process of problem solving by employing theoretical models and action-based research methods.

- Current with technology relevant to pedagogy: The leader should be interested in new trends regarding pedagogical uses of technology and be up-to-date. 
- Ability to suggest suitable technology for specific contents and contexts: The leader should be rooted in local contexts and understand the affordances for teachers and students in different content areas.

- 21 st century learning skills: The leader should demonstrate excellent skills with regard to lifelong-learning strategies, technology-related skills, information literacy, computational thinking and other related abilities.

- Reflective practitioners: The leader is able to reflect on personal practice in-action and on-action and adapt his/her own practice according to the conclusions.

- Openness and willingness to encourage others with passion: The leader cares for fellow colleagues and wants to serve for others' improvement including within his/her own local community and beyond to other professional groups.

- Broad focus on different technologies: The leader does not focus on one technology alone but is able to provide a broad menu of multiple options that is constantly updated.

- Knowledge about change and management of change: The leader should be aware of theories of educational change and demonstrate different strategies for managing change.

- Empowerment of others: The learning leader should be open to collaboration and a distributed leadership model.

There are likely other characteristics that may be related to learning leaders who innovatively use technology to enhance learning. This list is a starting point that allows identification of effective learning leaders and possibly future leaders whose strengths can be continually enhanced and refined through professional development activities. 


\section{Effective Leadership Styles}

Leadership has been defined as an interpersonal process to influence people in groups to strive for a common goal (Northouse, 2016; Yukl, 2012). Leadership drives change processes of varying scope, where it deals with different types of resistance to change and stress - ranging from silent and passive avoidance to articulate and open opposition (Bovey \& Hede, 2001; Mishra \& Spreitzer, 1998). While leadership was traditionally attributed to the ability of charismatic individuals to exert some sort of persuasive power, this view has changed considerably. The classical study of Lewin (1943) was the first to show that change comes more readily, when affected persons take an active part in decision-making, when they are part of a group, when cooperation takes place and when there are steps in addressing the change. Since then, the importance of participatory and distributed leadership has been shown in numerous studies and addressed in many leadership theories, in particular the theory of transformational leadership (Bass, 1990; Burns, 1978).

Transformational leadership relies on four major components: 1) being a credible model of change, 2) motivating by creating a shared vision, 3) encouraging independent and creative thinking and 4) providing individual support. Transformational leadership has been contrasted by theories of transactional leadership, which are more top-down, relying on set-goals, contingent rewards and management by exception (Howell \& Avolio, 1993). Transformational leadership traits include a shared decision making approach among stakeholders, including teachers. Meta-analyses suggest that both transformational and transactional leadership styles are more effective than laissez-faire 
and passive types of leadership and although transformational leadership seems to be slightly more effective than transactional leadership, both styles are positively correlated and can also be combined (Judge \& Piccolo, 2004; Wang, Oh, Courtright, \& Colbert, 2011).

Transformational leadership has also been successfully applied to change processes in schools (Leithwood, Harris, \& Hopkins, 2008). Furthermore, technologyrelated leadership styles need to take the general culture of leadership within the school and the wider educational system into account. An effective leader must be aware of the wider issues to take not only the intended consequences of actions into account but also the by-products and unintended consequences. In a meta-analysis of 12 studies, Tan (2010) found a transformational style of leadership to be associated with higher levels of technology integration and use. In addition, international case studies have repeatedly shown that successful change processes with regard to educational technology were more likely when pedagogy and not technology was the driving force (Law, Pelgrum, \& Plomp, 2008; Venezky \& Davis, 2002). Therefore, it is important to remain focused on learning goals rather than technology. Leadership in educational technology integration encompasses aspects like a clear vision, changes in the curriculum, adequate resources and staff development, and these leadership roles can be distributed across schools principals, technology experts, teachers, parents and even students (Anderson \& Dexter, 2005; Davies, 2010).

\section{Roles of Learning Leaders}

The role of learning leaders in the education system varies by school system but those who have the most local impact on the students are critical for learning. This section will 
focus on principals and teacher leaders and their role in creating an effective learning environment.

\section{Principals as professional learning leaders for technology enhanced learning}

School leaders are instrumental in the implementation and integration of technology in their schools as the holders of status and engagement with faculty and the larger community of parents and other stakeholders (Whitehead, Jensen, \& Boschee, 2003). School principals are responsible for leading, navigating and changing schools to include modern, digital content in a changing technological environment. "To lead successfully in the twenty-first century, administrators will have to address the ubiquitous nature of technology, bring it into their schools to be used as a tool for learning and accommodate students and teachers who are accustomed to using technology as a tool for learning both inside and outside the classroom" (Schrum \& Levin, 2012, p.21). Often these school leaders have not been prepared in their university educational leadership programs to lead technology innovations. Their role has changed significantly in the past decade and often preparation to lead with technology was absent or very fragmented. School principals have typically been charged with setting the vision for the school but now the vision must include the integration of digital tools for learning. As discussed earlier in this paper, transformational leaders who include shared decision-making are associated with higher levels of technology integration and use.

Principals, who are learning leaders, are charged with leading transformative approaches in schools rather than serving in a strictly administrative function. These leaders must be risk-takers, forward thinking, problem solvers and confident in their pedagogical understandings (Hew \& Brush, 2007; Pelgrum, 1993). Leading technology- 
enhanced learning must move beyond a management approach toward the role of the learning leader being a change agent for technology adoption to be innovative and implicit within teaching and learning in a school (Fullan, 2014; Leithwood \& Riehl, 2003; Macneill, Cavanagh, \& Silcox, 2005). School leaders should create changeoriented environments supporting experimentation and innovation, as well as include teachers in the decision-making processes (Reio \& Lasky, 2007) for sustainability and ownership of such change.

To support technology use, the school principal should first develop a vision of how school reform will be influenced by technology use (Chang, 2012). Creating a vision can improve pedagogical processes for overall learning goals. Examples of vision-based goals for implementing technology for enhanced learning include: a) students experience technology as a meaningful learning tool; b) students show improved motivation and academic performance; and c) students show increased technological skills. The development of a sound vision requires that the school principal understand the potential benefits and can articulate how and why technology used in particular ways will enhance learning (Bridges, 2003; Chang, 2012). In this way pedagogical thinking leads to decisions on including technologies that will benefit the curriculum. Effective implementation of a vision can be facilitated by other aligning factors. For example, Alghamdi and Prestridge (2015) suggest that principals' and teachers' pedagogical beliefs about technology should align to ensure more effective integration. The alignment of beliefs among these stakeholders can make leading school wide reform less challenging. Leadership practices such as 
developing a shared vision, shared ownership and share responsibility for curriculum design and technology integration, requires shifts in ways of thinking and beliefs amongst all stakeholders for beneficial outcomes.

Identifying potential classroom-level change agents is another important aspect of vision implementation. School principals typically are charged with the overall responsibility to ensure that instructional goals of their school are met. These leaders also work closely with classroom teachers and are best equipped to possibly identify those teachers who exhibit leadership characteristics and are adept at integrating technology for learning. Once identified, principals can create teams of leaders who can carry out the changes envisioned throughout the school learning environments providing on-going support for these agents of change.

\section{Teachers as professional learning leaders for technology enhanced learning}

Teacher leaders have been defined by Riel and Becker (2008) as teachers who have strong professional engagement with other teachers both locally and at a distance, across a range of activities and domains. These teacher leaders were found to be ten times as likely to be designated as exemplary technology integrators in a school, when compared to a traditional teacher (Riel \& Becker, 2008). Encouraging and developing teachers as leaders can assist in creating an environment of innovative learning with technology (Hughes \& Zachariah, 2001). Classroom teachers who are learning leaders were further described by Riel \& Becker (2008) as having behaviors reflecting a high level of engagement with the profession of teaching and with other teachers. Teacher leaders 
were found to be more constructivist in their teaching style and to have used substantially more technology than those teachers who were defined as traditional teachers.

Researchers also found that these teacher leaders were more likely than traditional teachers to place emphasis on higher cognitive processes for learning and to use more active learning strategies (Riel \& Becker, 2008). Some of the defining traits of these learning leaders included learning from one's own teaching, collaborating and sharing responsibility for student success, participating in diverse communities of practice and making personal contributions to the teaching profession. Riel and Becker (2008) found a high correlation between teacher leaders and innovative technology users. Teacher leaders used technology in more sophisticated ways to impact learning.

Teachers who believe in the positive learning benefits of technology-enhanced learning are more likely to persist to overcome first order barriers, such as access and time constraints (Ertmer \& Ottenbreit-Leftwich, 2013). These teachers often are the ones who experiment over time to refine the ways technologies are used (Ertmer, OttenbreitLeftwich, Sadik, Sendurur, \& Sendurur, 2012). Dweck's (2010) growth mindset, that acknowledges effort and resilience for prosperous outcomes, can be applied to these teachers. This shaping and reshaping of pedagogies have been described as a reforming process of teachers' beliefs and practices that are motivated to change as they implement technologies (Prestridge, 2017a).

Leading with technology-enhanced learning involves demonstrating innovative practices in the classroom. Leading also involves supporting teacher colleagues to grow, develop, and be engaged with these practices (Riel \& Becker, 2008). At the core of such a proposition are leaders as mentors and knowledgeable colleagues who collaborate 
alongside rather than in front of their peers. The benefits of collaborating have been analyzed by Blitz (2013) through teachers' engagement in professional learning communities. These communities are based around improving student learning outcomes through response driven change enabled through by collaborative interchanges. As a professional learning process to improve pedagogical practice, teacher collaborative activities have been shown to provide a space and place for dialogue that supports the growth of new ideas (Meirink, Imants, Meijer, \& Verloop, 2010), improve technological competencies (Egodawatte, McDougall, \& Stoilescu, 2011) and broaden teaching strategies (Shipley, 2009). Fundamentally, teacher leaders are co-designing, coconstructing, critiquing, participating in teams, special interest groups, in professional networks with colleagues online, in schools and across districts providing evidence of leading through many forms of collaboration.

For teacher leaders, Riel \& Becker (2008) have described a style of leadership that aligns closely to the idea of transformational leadership. These teacher leaders are unique leaders as they are seen as rooted within their own school culture as well as in a community of specialists on a larger scale. The transformational leadership style seems to be more promising for teacher leaders than the transactional style that typically requires a higher ranked position within a hierarchical organization. However, findings suggest, that to be an effective teacher leader support is required by the school administration, especially with regard to sufficient time and resources as well as opportunities for professional development (York-Barr \& Duke, 2004).

\section{Preparation of Learning Leaders to Enhance Learning with Technology}


This section will include the discussion of ideas related to supporting and preparing learning leaders who have the most direct impact on student learning. The objective is that learning leaders are prepared and supported to enable a systemic change process. Learning leaders need to be directed and supported to facilitate the building of a school vision. To enable ownership of this shared vision, the leader needs to take part in establishing a change process that includes the collaborative building of short and longterm goals and models distributed leadership (Snoek, 2014). It is important to note that learning to lead is a transformational process that does not occur in a one-time course or one-time professional development session.

Innovative professional development for leaders is crucial for success. While there are many formal and informal methods of preparation, the professional development opportunities for learning leaders can benefit from being underpinned by the development of leadership capacity through a professional learning community. Leaders can engage in many formal training sessions, workshops and or online courses to enhance their leadership skills. Being part of a wider community of like-minded colleagues can help leaders negotiate both external and school based professional development activities into leadership and learning practices. This leader community can be online and/or face-to-face, inclusive of leaders from a number of schools so that cosupport and collaboration amongst the participants occurs (Trust, Krutka \& Carpenter, 2016; Visser, Evering, \& Barrett, 2014). Within the community, the teacher should be encouraged to take on an action research process, contributing ideas, sharing evidence, as well as planning and developing processes and strategies for school reform. Leaders can learn from one another, building on ideas and reforming their own approaches. 
Fundamentally, the learning community should be an active organization that informs and supports leaders to lead change.

While leader preparation programs may be beneficial in preparing school leaders, few educational leadership programs include technology as an integral role in the leadership process. One challenge in preparing ICT school leaders is creating a system that includes a cycle of inquiry that supports leaders while leading in their often very unique schools. Experts in leadership agree that "professional development activities should be on-going, career-staged and seamless" (Davis, Darling-Hammond, LaPointe, \& Meyerson, 2005). Programs should be tailored to local conditions as well as global standards (i.e. the program should be situated in context, culture, and local conditions for the success). Effective leadership development programs should be collaborative in nature and include networking among participants, which can help to foster collaborative problem-solving and alleviate the sense of isolation that some school leaders feel (Schleicher, 2012). Collaboration and knowledge exchange between ICT leaders at schools and their mentors is also an important factor.

Technology leadership is a combination of general techniques and strategies with some specifications including the use of new knowledge, skills, and understanding of how technology can improve instructional practice and the administrational processes (Staples, Pugach, \& Himes, 2005). While many classroom teachers may have leadership qualities, they have likely not been allowed the freedom to use these skills in a broader environment in their schools. Development of these identified teacher leaders allows a team-based approach to realizing the school vision. Professional development should equip teacher leaders with a variety of skills in response to specific needs, to allow 
leaders and leadership teams to update their skills and/or share new practices. Preparation for learning leaders is an on-going process and should be updated frequently in response to continuing and rapid developments in information technology. As Fullan stated "we do not know very clearly what good quality use will look like or what the real impact on students will be. So, boards, principals and teachers do not have clear guidelines. Furthermore, NET (New Educational Technologies) hardware and software are changing and developing continuously. We must invent our own future" (Fullan, 1991, p. 55).

As we see informal education taking a larger role in our educational process, we must also look at informal professional development. Professional networks can also be used to develop school leaders and leadership teams informally. Virtual networks can also help school leaders to share best practices. More and more educators in the K-12 environment are using social media and mobile technology as part of their personal learning networks. We see most conferences across the world having "back channels" and hashtags as part of the total learning experiences for attendees. These experiences have engaged many more educators in thinking more deeply about what they are learning from their conference. At a recent Mobile Learning Conference held at UNESCO, in Paris, France (UNESCO, 2017), case after case was stated about how teachers of refugee students were using mobile devices and apps to help share lesson plans as well as their best teaching practices. Dr. Joe Sanfelippo, Superintendent (school system leader), believes that informal professional development through social media is vital for all educators: "Twitter is my go to...always my first choice for PD. Great way to connect and learn. You can also archive your learning through hashtags, which really helps if you are trying to find something later. This is the best way for me to develop my personal 
learning network" (Sanfelippo, 2017). Research in this field suggests that the professional learning landscape has shifted greatly with on-demand, 24/7 learning delivery (Simonson, Schlosser, \& Orellana, 2011; Trust et al., 2016). Informal professional development is being adopted by many educators around the world that may lead to the transition of informal professional development toward it becoming more integrated actively in formal approaches.

Fundamentally, the move to self-directed professional learning provides greater possibilities in developing one's own needs and interests but also and more significantly, the possibility for leaders to contribute to the growing community's knowledge (Prestridge \& Tondeur, 2015). In this way teacher leaders do not just consume content but rather through active participation in an online community, they contribute to the growing knowledge of that community and can collaborate, co-design and mentor colleagues (Prestridge, 2017b).

\section{Innovative Models and Practices for Creating Leaders}

Innovative models for developing learning technology leaders need to be underpinned by notions of pedagogical and curriculum change, personal qualities of adaptability, drive and resilience as well as professional qualities of collaboration, mentoring and contribution. No longer can professional approaches sustain models of learning that are based on 'experts' delivering content to teachers replicating traditional top-down training based on the assumption that "teachers need direct instruction about how to improve their skills and master new strategies" (Lieberman \& Miller, 2014, p. 7). Models or approaches founded on this premise provide little to those teachers who are leading with technologies 
in their schools. Professional development needs to equip leaders to act as shapers, promoters and well-informed critics of innovations and reform (Little 1999).

Creating leaders who are able to motivate, communicate and facilitate the development of other stakeholders in the implementation of the vision of the school is critical for sustaining a thriving digital culture in education. Researchers in the educational leadership field have suggested that it is important to make a distinction between a leader and a manager for innovative change in educational systems (Franciosi, 2012). As described above, distinction is further made between transformational leadership, versus transactional leadership, with the former judged to be a better model for successful technology enhanced learning in schools.

One exemplar that innovatively prepares learning leaders to support learning with the use of technology is the Team Master Transition in Education with Technology (3TO) program in the Hague district of The Netherlands. The program was developed by the Lucas Education Organization in cooperation with Leiden University of Applied Science. Lucas Education provides education for 33,000 students and has 3,900 teachers and other employees and is one of the largest education boards in the Netherlands. This program was inspired by Michael Fullan's ideas about collective capacity that when groups work together, an emotional commitment and the technical expertise is generated that no amount of individual capacity working alone can come close to matching (Fullan, 2010). This program includes a team-based approach to change the way leaders are educated in order to create sustainable change in the way students learn through a team-based approach. Each school-based team of 3-6 educators must include the head of the school and teachers who are committed to innovative change that includes technology. Within 
their school teams, teachers and schools are expected to engage in continuous development that translates into the best possible education for students. An accompanying, new team-based masters' program includes equal collaboration between Lucas Education and Leiden University of Applied Sciences which is a rather unique collaboration between a university and practitioners.

As far as the developers of this masters' degree are concerned, contemporary education cannot exist without meaningful application and support of technology. That is why the role of technology is crucial within the program. The participants learn how to shape and guide transition in education. They implement a significant change process in their own schools as an integrated part of the course creating a multiple effect: experience is gained through the process of change, and an actual development takes place in their own school. Because the design of the masters' is based on team effort and strength, participation in the program can only take place when several team members and a board member of the same school jointly enroll; individual participation is not possible. The program focuses on teams that want to get started with a transition issue in their own school and on teachers and school leaders who want to develop as or become leaders.

One of the most characteristic starting points of the course is that the learning themes of a school are determined together by participants and course leaders. This form of co-creation also applies to the working relationship between the $3 T O$ team and the school community that includes parents and students. A learning theme is based on the developmental question of the school and is different for each participating school, as it is adapted to the needs and possibilities within that particular school. Once the learning theme is determined, it is approached from three different, although interlinked angles: 
team development, transition, and technology. During the two-year course teams commit to two days a week, including one for a university course and one for independent study. Every month one of the course days is set aside as an open space, in which emerging questions or ideas can be worked out either at the university, in school, or elsewhere. A culture of innovation is practiced and applied in this way with the knowledge that the masters' student grows from skills to habits.

One of the challenges in this team approach is that such a degree is linked to a person and not to a group. But the heart of the masters' program revolves around the team effort to realize a transition in the school and to be a teacher leader. To deal with this contradiction, assignments are marked as group assignments or as individual assignments. All assignments are rewarded within the European Credit Transfer System (ECTS). Students need to obtain both individual study points and group points. To ensure the quality of both the team effort and the individual study results, a variety of assessment tools are used. The study results are described as learning outcomes, at the individual level and at the team level. A final product has been appointed for every learning outcome and a student will present evidence to show that (s)he has achieved these learning outcomes while the $3 T O$ team also demonstrates that they have achieved the outcomes. The team and the individual students are both responsible to achieve the results. Evaluation and assessment measures are built into the program to not only measure progress but provide feedback to improve the team-based model for school innovation.

\section{Assessing Leadership Impact}


The impact of learning leaders should be seen as the effects that are generated based on the targeted interventions that were intended to target needed change. Leaders must embed these actions in a continuous cycle of collaborative vision creation regarding intended, improved activities and systems in the future. Leaders should also provide operational guidance on how to design, implement and assess actions that work for achieving a targeted future outcome. If learning leaders explore new possibilities for technology enhanced learning, leaders need to assess these possibilities in order to provide evidence of success in enhancing learning. Leaders also need to include an assessment of those contexts or learners for which technology-enhanced learning might not work and why.

In order for assessment to have a scientific basis, evaluation should occur according to validated methods. These might include the involvement of $4^{\text {th }}$ generation or realistic evaluation methods that emphasize the collaborative reconstruction and explanation of how and what really was generated on the basis of interventions and what outcomes resulted (Guba \& Lincoln, 1989; Pawson \& Tilley, 1997). Learning dialogues between stakeholders on improving opportunities for learning are crucial for achieving consensus on the question 'What does or does not work for whom under what circumstances and why?' (Pater, Sligte, \& van Eck, 2012).

Assessment accompanies interventions from the point when leaders realize change is needed. Interventions designed to improve technology-enhanced learning form a change strategy. Right from the start of an intervention, evaluation is aimed at specifying the underlying theory for change and its assumed impact, thus offering a framework for testing and proving the hypotheses behind the intervention. During 
introduction and implementation of the interventions, formative assessment or process evaluation occurs allowing continual assessment of the changes. Including feedback from all stakeholders (interviews, focus groups) is crucial in determining whether the intervention works out as intended, and what adjustments are needed.

In the end the outcomes of interventions initiated and supported by learning leaders are to be assessed with respect to the diverse context-dependent conditions and factors for success and failure. Some interventions aimed at improving learning are successful in certain contexts (classrooms, schools, districts, countries) and not in other contexts. The effects of interventions should be credible and trustworthy to the stakeholders. While quantitative outcomes of the intervention should be measured and analysed, qualitative assessment and realistic validation by stakeholders belonging to a distinct context must be included as well.

Lessons are to be drawn to further improve technology-enhanced learning and its organization and support systems in subsequent cycles. In these times in which technology keeps on developing - with its merits for learning and instruction, and its promises and challenges for future competent participation in work and society - it is vital to focus on continuous and sustainable innovating as a process, rather than on technological innovations.

Interventions may be based on achieving standards professional organizations have proposed, such as the ISTE standards for administrators and UNESCO framework previously presented in this paper. ISTE has been known for creating standards for learning leaders, such as: a) establishing visionary leadership to inspire, engage and advocate, $b$ ) establishing a digital age learning culture that includes creating a learner- 
centered environment to support meeting diverse needs of learners, and c) maintaining excellence in professional practice intended to promote an environment of empowerment for educators (ISTE, 2011). These standards relate to advocating for students, mentoring new teachers, informing others/sharing knowledge, connecting with community, connecting with parents and families, teaching others, communicating/advocating and collaborating with others. The UNESCO framework and ISTE standards may be used to create formative assessment tools to guide innovative changes intended in an intervention.

Scientific methods for evaluating interventions and their actively working components are vital to assess the impact of learning leaders. But applying these methods should not merely be in the hands of researchers. Teachers and administrators acting as learning leaders can apply these research methods, as demonstrated in a scientific study on teachers' use of and reasoning about technology in practice (Voogt, Sligte, van den Beemt, Van Braak, \& Aesaert, 2016). By reasoning about the intended added value of technology for learning, and assessing what really works for their contexts, teachers and administrators are being both reflective practitioner and action researcher in order to find out what works for whom and in what situations concerning technology-enhanced learning.

\section{Summary and Discussion}

To lead successfully in the $21^{\text {st }}$ century, learning leaders must consider the ubiquitous nature of technology and find innovative ways to ensure its successful implementation in learning. "Transformational leadership focuses on developing the organization's capacity 
to innovate... focuses on developing a shared vision and shared commitment to school change" (Hallinger, 2003, p.330). Whether learning leaders include classroom teachers, principals or other education roles, their main focus is on student learning and how best to prepare students for the $21^{\text {st }}$ century. Effective leaders exhibit the ability to create a shared vision, remain pedagogically focused, and seek and contribute to on-going professional development.

One challenge in preparing learning leaders is in tailoring the program for local context, culture and conditions. Not only is technology integration important for improving student learning, it also plays a vital role in on-going, informal learning networks of learning leaders. Innovative professional development for leaders is crucial for success and dialogue in an online environment and allows others to learn from these practices. Additionally, it is becoming more important to recognize the value of the leader's informal learning.

Many challenges remain to be addressed en route to developing the full educational potentials for benefit from learning leaders. How are teachers who become learning leaders compensated (or released from some of their previous teaching loads) when they become recognized as learning leaders? How are principals who spend more of their time with teachers, encouraging technology-enhanced learning, evaluated as managers of the business of education, by their supervisors and their peers? Innovative professional development for leaders is crucial for success in advancing the state of the art for developing learning leaders to their highest capacity. Yet mechanisms incorporating this aspect as a fundamental component of an educational system scarcely exist. The availability of readily accessible mechanisms for dialog in online environments 
would appear to provide a very low threshold for others to learn from established learning leaders' best practices, and may be one mechanism that would offer a beginning path for most educational systems. Another possible avenue is through meetings such as EDUSummIT that include researchers, policy makers and practitioners and occur to determine action-based outcomes to find solutions for authentic problems faced in schools. Disseminating the outcomes from such groups is an important action that allows others to continue in their efforts to improve the learning process.

\section{References}

Alghamdi, A., \& Prestridge, S. (2015). Alignment between principal and teacher beliefs about technology use. Australian Educational Computing, 30(1).

Anderson, R.E., \& Dexter, S. (2005). School technology leadership: An empirical investigation of prevalence and effect. Educational Administration Abstracts, 40(3), 49-82.

Bass, B.M. (1990). From transactional to transformational leadership: Learning to share the vision. Organizational dynamics, 18(3), 19-31. doi:10.1016/00902616(90)90061-s

Blitz, C.L. (2013). Can online learning communities achieve the goals of traditional professional learning communities? What the literature says. REL 2013-003. Regional Educational Laboratory Mid-Atlantic.

Bovey, W.H., \& Hede, A. (2001). Resistance to organizational change: the role of cognitive and affective processes. Leadership \& Organization Development Journal, 22(8), 372-382. doi:10.1108/01437730110410099. 
Bridges, J.W. (2003). Principal influence: Sustaining a vision for powerful new forms of learning using technology. Doctoral Dissertation. University of California at Los Angeles.

Burns, J.M. (1978). Leadership. New York, NY: Harper \& Row.

Chang, I. H. (2012). The effect of principals' technological leadership on teachers' technological literacy and teaching effectiveness in Taiwanese elementary schools. Journal of Educational Technology \& Society, 15(2), 328-340.

Davies, P.M. (2010). On school educational technology leadership. Management in Education, 24(2), 55-61. doi:10.1177/0892020610363089

Davis S., Darling-Hammond, L., LaPointe, M., \& Meyerson, D. (2005). Review of research, school leadership study: Developing successful principals. Stanford Educational Leadership Institute and the Wallace Foundation, Stanford.

Dawson, K., \& Rakes, G. (2003). The influence of principals' technology training on the integration of technology into schools. Journal of Research on Technology in Education, 35, 29-49.

Dweck, C.S. (2010). Mind-sets. Principal Leadership, 10(5), 26-29.

Egodawatte, G., McDougall, D., \& Stoilescu, D. (2011). The effects of teacher collaboration in Grade 9 applied mathematics. Educational Research for Policy and Practice, 10, 189-209. doi:10.1007/s10671-011-9104-y.

Ertmer, P.A., \& Ottenbreit-Leftwich, A. (2013). Removing obstacles to the pedagogical changes required by Jonassen's vision of authentic technology-enabled learning. Computers \& Education, 64,175-182. 
Ertmer, P.A., Ottenbreit-Leftwich, A.T., Sadik, O., Sendurur, E., \& Sendurur, P. (2012). Teacher beliefs and technology integration practices: A critical relationship. Computers \& Education, 59(2), 423-435.

Franciosi, S.J. (2012). Transformational leadership for education in a digital culture. Digital Culture \& Education, 4(1), 235-247.

Fullan, M. (1991). The new meaning of educational change. London: Cassell.

Fullan, M. (2001). Leading in a culture of change. San Francisco, CA: Jossey-Bass.

Fullan, M. (2010). All systems go. Thousand Oaks, CA: Corwin.

Fullan, M. (2014). The principal: Three keys to maximizing impact/Michael Fullan. San Francisco, CA: Jossey-Bass.

Guba, E.G. \& Lincoln, Y.S. (1989). Fourth generation evaluation. Newbury Park, California: Sage Publications.

Hallinger, P. (2003). Leading educational change: Reflections on the practice of instructional and transformational leadership. Cambridge Journal of Education, 33(3), 329-352. doi:10.1080/0305764032000122005.

Harasim, (2012). Learning theory and online technologies. New York: Routledge.

Hew, K.F., \& Brush, T. (2007). Integrating technology into K-12 teaching and learning: Current knowledge gaps and recommendations for future research. Educational Technology Research and Development, 55(3), 223-252. doi:10.1007/s11423-006.

Howell, J.M., \& Avolio, B.J. (1993). Transformational leadership, transactional leadership, locus of control, and support for innovation: Key predictors of consolidated-business-unit performance. Journal of Applied Psychology, 78(6), 891-902. doi:10.1037/0021-9010.78.6.891. 
Hughes, M., \& Zachariah, S. (2001). An investigation into the relationship between effective administrative leadership styles and the use of technology. International Electronic Journal for Leadership in Learning (IEJLL), 5(5).

Hutchison, A., \& Reinking, D. (2011). Teachers' perceptions of integrating information and communication technologies into literacy instruction: A national survey in the United States. Reading Research Quarterly, 46(4), 312-333.

ISTE Standards for Administrators. (2011). NET•S for Administrators. www.iste.org/standards/standards/standards-for-administrators

International Society for Technology in Education (ISTE). (2018). ISTE standards for administrators. Available from https://www.iste.org/standards/for-administrators

Jacobson, M.J., So, H-J., Teo, T., Lee, J., Pathak, S., \& Lossman, H. (2010). Epistemology and learning: Impact on pedagogical practices and technology use in Singapore schools. Computers \& Education, 55(4), 1694-1706.

Judge, T.A., \& Piccolo, R.F. (2004). Transformational and Transactional Leadership: A Meta-Analytic Test of Their Relative Validity. Journal of Applied Psychology, 89(5), 755-768. doi:10.1037/0021-9010.89.5.755

Law, N., Pelgrum, W., \& Plomp, T. (2008). Pedagogy and ICT use in schools around the world. Findings form the IEA SITES 2006 Study. Hong Kong: CERC / Springer.

Leithwood, K., Harris, A., \& Hopkins, D. (2008). Seven strong claims about successful school leadership. School Leadership and Management, 28(1), 27-42. doi:10.1080/13632430701800060

Leithwood, K.A., \& Riehl, C. (2003). What we know about successful school leadership. Nottingham, UK: National College for School Leadership. 
Lewin, K. (1943). Forces behind food habits and methods of change. Bulletin of the National Research Council, 108, 35-65.

Lieberman, A., \& Miller, L. (2014). Teachers as professionals: Evolving definitions of staff development, in L. Martin, S. Kragler, D. Quatroche \& K. Bauserman, K (Eds.). Handbook of professional development in education: Successful models and practices, Prek-12. Guilford Publications. Chapter 1. 3-21.

Little, J.W. (1999). Organising schools for teacher learning. In L. Darling-Hammond \& G. Sykes (eds.), Teaching as the learning profession: Handbook of policy and practice (233-262). San Francisco: Jossey Bass.

Loveless, A. (2003). The interaction between primary teachers' perceptions of ICT and their pedagogy. Education and Information Technologies, 8(4), 313-326

Macneill, N., Cavanagh, R.F., \& Silcox, S. (2005). Pedagogic leadership: Refocusing on learning and teaching. IEJLL: International Electronic Journal for Leadership in Learning, 9(2).

Meirink, J.A., Imants, J., Meijer, P.C., \& Verloop, N. (2010). Teacher learning and collaboration in innovative teams. Cambridge Journal of Education, 40, 161-181.

Mishra, A.K., \& Spreitzer, G.M. (1998). Explaining how survivors respond to downsizing: The roles of trust, empowerment, justice, and work redesign. Academy of Management Review, 23(3), 567-588. doi:10.2307/259295.

Northouse, P. G. (2016). Leadership: Theory and Practice (7. Ed.). Singapore: Sage publications.

Pater, C., Sligte, H., \& van Eck, E. (2012). Verklarende evaluatie, een methodiek. [Explanatory evaluation, a method] Amsterdam: Kohnstamm Instituut. 
Pawson, R. \& Tilley, N. (1997). Realistic evaluation. London: SAGE Publications.

Pelgrum, W.J. (1993). Attitudes of school principals and teachers towards computers:

Does it matter what they think? Studies in Educational Evaluation, 19(2), 199-212. doi:10.1016/0191-491X(93)90007-E9022-5.

Prestridge, S. (2007). Engaging with the transforming possibilities of ICT: A discussion paper. Australian Educational Computing, 22(2), 3-9.

Prestridge, S. (2017a). Examining the shaping of teachers' pedagogical orientation for the use of technology. Technology, Pedagogy and Education, 26(4), 367-381.

Prestridge, S. (2017b). Conceptualising self-generating online teacher professional development. Technology, Pedagogy and Education, 26(1), 85-104. doi: 10.1080/1475939X.2016.1167113.

Prestridge, S., \& Tondeur, J. (2015). Exploring elements that support teacher's engagement in online professional development. Education Sciences, 5(3), 199-219.

Reio, T.G., Jr., \& Lasky, S.L. (2007). Teacher risk taking changes in the context of school reform: A sociocultural and cognitive motivational perspective. In D. M. McInerney \& S. Van Etton (Eds.), Standards in education: Vol. 7. Research on sociocultural influences on motivation and learning. (pp. 13-32). Charlotte, NC: Information Age Publishing.

Richardson, J.W., Flora, K., \& Bathon, J. (2013). Fostering a school technology vision in school leaders. National Council of Professors of Educational Administration (NCPEA) International Journal of Educational Leadership Preparation, 8(1), 144161. 
Riel, M., \& Becker, H. (2008). Characteristics of teacher leaders for information and communication technology. In J. Voogt and G. Knezek (eds.) International Handbook of Information Technology in Primary and Secondary Education, pp. 397-417. New York: Springer.

Sanfelippo, J. (2017). Keynote address: Future Ready Schools Institute, November 14$15,2017$.

Schleicher, A. (ed.) (2012). Preparing Teachers and Developing School Leaders for the 21st Century: Lessons from around the World, OECD Publishing, Paris. doi.org/10.1787/9789264174559-en.

Schrum, L., \& Levin, B.B. (2012). Evidence-based strategies for leading $21^{\text {st }}$ century schools. Thousand Oaks, CA: Sage.

Shipley, W. (2009). Examining teacher collaboration in a kindergarten building: a case study (Unpublished doctoral dissertation). Duquesne University, Pittsburgh.

Simonson, M., Schlosser, C., \& Orellana, A. (2011). Distance education research: A review of the literature. Journal Of Computing In Higher Education, 23(2-3), 124142.

Snoek, M. (2014). Developing teacher leadership and its impact in schools. Digital Academic Repository, University of Amsterdam.

Staples, A, Pugach, M.C., \& Himes, D. (2005). Rethinking the technology integration challenge: Cases from three urban elementary schools. Journal of Research on Technology in Education, 37(3), 285-311.

Stuart, L.H., Mills, A.M., \& Remus, U. (2009). School leaders, ICT competence and championing innovations. Computers \& Education, 53(3), 733-741. 
Tan, S.C. (2010). Technology leadership: Lessons from empirical research. Ascilite (p 891-895). Sydney, Australia.

Thomas, L. \& Knezek, D. (2008). Information, communications, and educational technology standards for students, teachers, and school leaders. In J. Voogt, \& G. Knezek (Eds.), International Handbook for Information Technology in Primary and Secondary Education. Amsterdam: Springer Verlag, 2008, pp. 333-347.

Trust, T., Krutka, D.G., \& Carpenter, J.P. (2016). “Together we are better”: Professional learning networks for teachers. Computers \& Education, 102, 15-34.

UNESCO. (2011). UNESCO ICT competency framework for teachers. Paris, France: United Nations Educational, Scientific and Cultural Organization. Available http://www.unesco.org/new/en/unesco/themes/icts/teacher-education/unesco-ictcompetency-framework-for-teachers.

UNESCO. (2017). ICT in education: Mobile learning week. Paris, France, March 20-24. Available http://www.unesco.org/new/en/mlw.

Venezky, R.L., \& Davis, C. (2002). Quo Vademus? The Transformation of Schooling in a Networked World. Retrieved from http://www.oecd.org/dataoecd/48/20/2073054.pdf

Visser, R.D., Evering, L.C., \& Barrett, D.E. (2014). \#TwitterforTeachers: The implications of Twitter as a self-directed professional development tool for K-12 teachers. Journal of Research on Technology in Education, 46(4), $396 \mathrm{e} 413$. http://dx.doi.org/10.1080/15391523.2014.925694. 
Voogt, J., Sligte, H.W., Beemt, A. van den, Braak, J. van, Aesaert, K. (2016). Edidactiek. Welke ict-applicaties gebruiken leraren en waarom? [E-didactics. What ICT-applications do teachers use and why?] Amsterdam: Kohnstamm Instituut.

Voogt, J. Fisser, P., Tondeur, J., \& Van Braak, J. (2012). Technological pedagogical content knowledge (TPACK) - a review of the literature. Journal of Computer Assisted Learning 28(6), DOI: 10.1111/j.1365-2729.2012.00487.x.

Wang, G., Oh, I.-S., Courtright, S. H., \& Colbert, A. E. (2011). Transformational Leadership and Performance Across Criteria and Levels: A Meta-Analytic Review of 25 Years of Research. Group \& Organization Management, 36(2), 223-270. doi:10.1177/1059601111401017.

Whitehead, B.M., Jensen, D., \& Boschee, F. (2003). Planning for technology: A guide for school administrators, technology coordinators and curriculum leaders. Thousand Oaks, CA: Corwin.

York-Barr, J., \& Duke, K. (2004). What do we know about teacher leadership? Findings from two decades of scholarship. Review of Educational Research, 74(3), 255-316. doi:10.3102/00346543074003255.

Yukl, G.A. (2012). Leadership in Organizations (8. Ed.). Harlow, GB: Pearson Education. 